Dr Mohamad Mikati, Department of Neurology, Division of Neurophysiology, Hunnewell 2, Children's Hospital, Boston, MA 02115).

COMMENT. This is the first description of truly familial alternating hemiplegia, a syndrome of unknown etiology. The authors favor neurovascular or metabolic, rather than epileptic mechanisms.

Sakuragawa $\mathrm{N}$ reports 23 cases in an excellent review article from the National Institute of Neuroscience, Ogawa Higashi-cho, Kodaira-shi, Tokyo 187, Japan ( Brain Dev Sept 1992; 14: 283-8). The classification of alternating hemiplegia as a migraine variant is discussed.

\title{
HEMIPLEGIA WITH SUPERIOR SAGITTAL SINUS THROMBOSIS
}

A 2-year-old boy who developed a thrombosis of the superior sagittal sinus due to inherited protein $S$ deficiency is reported from the Hospital de Cruces, Vizcaya, Spain. While recovering from pneumonia, the patient had symptoms of an acute disseminated intravascular coagulation disorder associated with sinus thrombosis, left hemiparesis, focal seizures, and thrombosis of the left femoral vein. The paresis resolved within two months. (Prats JM et al. Superior sagittal sinus thrombosis in a child with protein $\mathrm{S}$ deficiency. Neurology Dec 1992; 4.2: 2303-5). (Reprints: Dr Jose Maria Prats, Neuropediatric Unit, Hospital de Cruces, 48903 Baracaldo, Vizcaya, Spain).

COMMENT. Homozygous protein S deficiency, an autosomal dominant trait with partial penetrance, usually presents with purpura fulminans in the newborn period. Heterozygous cases are responsible for recurrent peripheral thromboembolisms mainly in adults. Cerebral venous thrombosis is a rare complication of protein $S$ deficiency, but should be considered in the etiology of acute hemiparesis in children.

\section{RASMUSSEN'S SYNDROME AND UVEITIS}

Two children with Rasmussen's syndrome complicated by asymptomatic uveitis are reported from the Royal Children's Hospital, Melbourne, Australia, and Montreal Neurological Institute, Montreal, Canada. A 10-year-old girl developed somatosensorimotor seizures affected her right leg and left sided acute uveitis. Epilepsia partialis continua, with onset 9 months later, was associated with right hemiparesis and cortical sensory loss, and dysphasia. EEG showed epileptic discharges in the left central region. CT revealed atrophy of the left hemisphere. Left frontal corticectomy failed to control seizures. The cortex showed chronic encephalitis. The second patient, a 5-year-old girl, had complex partial status epilepticus which responded to IV gammaglobulin, left facial weakness, and right sided uveitis. Right anterior temporal lobectomy revealed leptomeningeal inflammation. Seizures became intractable, and a 